\title{
A longitudinal study of lung function from 1 month to 18 years of age
}

\author{
Steve Turner, ${ }^{1}$ Shona Fielding, ${ }^{2}$ Dave Mullane, ${ }^{3}$ Des W Cox, ${ }^{3}$ Jack Goldblatt, ${ }^{3}$ \\ Lou Landau, ${ }^{3}$ Peter le Souef ${ }^{3}$
}

- Additional material is published online only. To view please visit the journal online (http://dx.doi.org/10.1136/ thoraxjnl-2013-204931)

1 Department of Child Health, University of Aberdeen, Aberdeen, UK

${ }^{2}$ Medical Statistics Team, University of Aberdeen, Aberdeen, UK

${ }^{3}$ School of Child Health, University of Western Australia, Perth, Australia

\section{Correspondence to}

Dr Steve Turner, Department of Child Health, University of

Aberdeen, Royal Aberdeen Children's Hospital, Foresterhill, Aberdeen AB25 2ZG, UK; s.W. turner@abdn.ac.uk

Received 6 December 2013 Revised 18 May 2014 Accepted 19 May 2014 Published Online First 2 June 2014

\section{SLinked}

- http://dx.doi.org/10.1136/ thoraxjnl-2014-205752

CrossMark

To cite: Turner $S$,

Fielding $S$, Mullane $D$, et al.

Thorax 2014;69.

1015-1020.

\section{ABSTRACT}

Background Our hypothesis was that factors associated with wheeze will be associated with changes in lung function trajectory between 1 month and 18 years of age.

Methods Measurements of lung function were made in individuals aged 1, 6 and 12 months ( $V^{\prime}$ maxFRC), and also at ages 6,12 and 18 years $\left(\mathrm{FEF}_{25-75}\right)$. Changes in lung function over time relative to sex, a history of asthma, maternal asthma and other factors were explored using random coefficient models.

Results Lung function (maximal flow at functional residual capacity in infants and $\mathrm{FEF}_{25-75}$ in children) was determined in 241 individuals at 1 month, 192 at 6 months, 164 at 12 months, 106 at 6 years, 183 at 12 years and 141 at 18 years. In the multivariable model, maternal asthma (mean reduction in lung function 9.8\%), flow limitation (mean reduction 17.4\%), infant atopy (mean reduction 12.6\%) and maternal smoking (mean reduction in lung function $8.1 \%$ ) were acting independently. When interactions with time were sought, the reduction in lung function associated with maternal asthma and infant atopy were consistent over time, but \% lung function increased in boys by a mean of $1 \% / y e a r$ compared with girls, in flow-limited individuals by $3.0 \% / y e a r$ and by $0.9 \% / y e a r$ for those exposed to maternal smoking during pregnancy compared to other cohort members.

Conclusions Decrements in lung function in 18-yearolds associated with maternal asthma and early onset atopy may be determined by 1 month of age. Low initial lung function in some individuals can 'recover' in some settings.

\section{INTRODUCTION}

Obstructive lung function in adulthood is characterised by recurrent wheeze and has been associated with abnormal spirometry established by childhood. ${ }^{1}{ }^{2}$ Correlations between reduced lung function in infancy and adulthood ${ }^{3}{ }^{4}$ suggests that the mechanism for airway obstruction in adulthood is active at an early stage of development, possibly even before birth. For example, premature infants have a reduced lung function relative to term infants, but growth in lung function remains parallel with term controls during preschool years. ${ }^{5}$ Furthermore, reduced fetal size in the first trimester, assumed to be a surrogate of infant lung size, has been linked to reduced lung function in childhood. ${ }^{6}$ Although, for a population, obstructive lung function may be determined in early life, there is evidence that factors which are active in later life may impact on the expected lung function trajectory.

\section{Key messages}

What is the key question?

- What factors are associated with changes in lung function between 1 month and 18 years of age?

\section{What is the bottom line?}

- Infant onset atopy, maternal asthma and maternal smoking multivariable were associated with persistently low lung function from 1 month of age.

\section{Why read on?}

- Individuals with expiratory flow limitation, and those exposed to maternal smoking during pregnancy, had initial decrements in lung function which resolved, and in boys, lung function was initially lower than in girls, but this difference reversed by 18 years of age.

Arguably the best example of changing trajectory in lung function is the association with smoking. Smoking is associated with a more rapid decline in lung function ${ }^{7}$ compared with the normal progressive decrease that occurs after the age of 25 years, ${ }^{8}$ and this decline can be ameliorated by smoking cessation. ${ }^{9}{ }^{10}$ Bronchial hyperreactivity, a common feature of asthma, also correlates with a more rapid age-related decline of lung function. ${ }^{8}$ Female sex may be important to the rise and then fall in lung function between childhood and adulthood. ${ }^{11} \mathrm{~A}$ faltering rise in spirometric measurements during childhood is associated with early onset respiratory symptoms ${ }^{11-13}$ suggesting common underlying mechanisms for early wheeze and for failure to attain expected maximal lung growth.

Due to the challenges in measuring lung function in infants and young children, there is little understanding of the factors associated with deviations from expected lung function trajectory in early life. Increased infantile weight gain may be one factor associated with a relative decline in per cent of predicted lung function during infancy. ${ }^{14}$ In a Danish study,${ }^{15}$ children with asthma had deficits in lung function at birth and at 7 years of age compared to their non-asthmatic peers, and the magnitude of deficit became greater between birth and childhood. 
Individuals in a birth cohort recruited in Perth, Australia, have undergone pulmonary function testing between ages 1 month and 18 years, ${ }^{4}$ and we have demonstrated a modest positive correlation between expiratory flows at ages 1 month and 18 years. ${ }^{4}$ Here we test the hypothesis that, in our cohort, risk factors for asthma will be associated with reductions in lung function over time.

\section{METHODS}

\section{Study design}

Women attending an antenatal clinic were invited to enrol their infant in a cohort study. There was no selection for parents with asthma or atopy. Maternal asthma was defined as an affirmative response to the question 'Have you ever had asthma diagnosed by a doctor?'16 Infants attended assessments at ages 1, 6 and 12 months where length, weight, infant lung function and skin prick reactivity were determined. At ages 6, 12 and 18 years, participants attended an assessment which included a respiratory questionnaire, spirometry and skin prick testing. Wheeze was defined as an affirmative response to the question 'Do you/your child ever sound wheezy and if yes, has this been present in the last year?' A history of asthma ever was determined from questionnaire responses completed at ages 6,12 and 18 years and defined as an affirmative response to the question 'Has your child/have you been diagnosed with asthma by a doctor?' Current smoking at 18 years was defined as a positive answer to the question 'Do you now smoke cigarettes?' All assessments of this cohort have been approved by our institutional ethics committee, and written consent was taken from the participants at age 18 years.

\section{Infant lung function testing}

The rapid thoraco-abdominal compression technique was used to measure maximal flow at functional residual capacity (V'maxFRC). Details of the technique are presented elsewhere. ${ }^{17}$ Briefly, an inflatable balloon was placed inside a non-distensible jacket and rapidly inflated at the end of a tidal inhalation. The mean of five technically acceptable measurements was reported. Per cent of predicted infant lung function values were derived using our own derived reference equation for V'maxFRC ${ }^{18}$ (adjusting for length, weight, age at testing, sex and maternal smoking during pregnancy).

\section{Skin prick testing}

The standard methodology was applied ${ }^{19}$ and positive and negative controls were used. The following allergens were used at all ages: cow's milk, egg white, rye grass and Dermatophagoides farinae. In childhood, reactivity was also assessed to the following: mixed grass; Dermatophagoides pteronyssinus; cat dander; dog dander; Alternaria alternans; and Aspergillus fumigates (allergen provided by Hollister-Stier, Elkhart, Indiana, USA). A positive reaction was defined as a weal $\geq 2 \mathrm{~mm}$ in diameter for infants and $\geq 3 \mathrm{~mm}$ after infancy or, in cases of dermatographism, a weal larger than the negative control. Infant atopy was defined as a positive reaction on $\geq 1$ infant assessment. ${ }^{20}$

\section{Spirometry}

Spriometry was measured using a portable spirometer (Pneumocheck Spirometer 6100; Welch-Allyn, Skaneateles Falls, New York, USA), international guidelines were applied to quality control. ${ }^{21}$ Spirometric values were expressed as per cent predicted using a standard reference population which adjust for age, sex and height. ${ }^{22}$

\section{Analysis}

$\chi^{2}$ Tests were used to determine differences between the whole cohort and subsets, whereof lung function was measured at all ages except 6 years, and also where lung function was measured at $\geq 3$ ages for the following variables: male sex, parental asthma, maternal smoking during pregnancy, active smokers at 18 years and flow limitation at 1 month. Percentage of lung function was compared between the groups described with Student $t$ test. Longitudinal measurement of lung function was the outcome, and explanatory variables were selected a priori due to association with increased risk for wheeze and/or reduced lung function within our cohort: infant atopy, ${ }^{4}$ maternal asthma, ${ }^{4}$ smoking, ${ }^{4}$ male sex, ${ }^{18}$ maternal smoking during pregnancy, ${ }^{18}$ and expiratory flow limitation at 1 month of age. ${ }^{23}$ To give our results a clinical relevance, a history of asthma was included as an explanatory variable. Based on our earlier observations of associations between V'maxFRC and $\mathrm{FEF}_{25-75}{ }^{42}$ the latter spirometric measurement was the principal index of lung function beyond infancy but $\mathrm{FEV}_{1}$ and FVC were also considered. Sex and maternal smoking were factors we wished to relate to longitudinal lung function but were also factors used to derive standardised lung function; therefore, for analyses where male gender and maternal smoking were included as variables, per cent predicted lung function values were derived coding all individuals as male and as having non-smoking mothers. For each outcome, a random coefficients model was fitted using an unstructured covariance. Time was modelled as continuous, but took the values $0.1,0.5,1,6,12$ and 18 to represent the ages (in years) of assessment. Initially, univariate models were fitted for each variable followed by a multivariable model which included all variables. Further details of these models are presented on the online supplement. Standard statistical software was used (IBM SPSS V.20 and SAS V.9.2), and a p value of $<0.05$ was assumed to be significant.

\section{RESULTS}

\section{Study subjects}

Lung function was determined in 241 individuals at 1 month (95\% of the original cohort), $192(76 \%)$ at 6 months and 164 (64\%) at 12 months of age, 106 (42\%) 6-year-olds, 183 (72\%) 12-year-olds and 141 (56\%) 18-year-olds. Lung function was measured at all six ages in 49 individuals and in 91 individuals at ages 1, 6 and 12 months and 12 and 18 years; these 91 individuals were less likely to have had flow limitation at 1 month and had higher lung function at 1 month and 6 years compared with the whole population, table 1 . There were 162 individuals with $\geq 4$ lung function measurements, who were more likely to have infant atopy, and also had higher $\% \mathrm{FEF}_{25-75}$ at 6 years compared with the whole cohort (table 1).

\section{Longitudinal assessment of lung function}

In univariate models, (fixed effects of time and the variable, random effect for patient and patient $\times$ time), reduced per cent lung function (V'maxFRC in infancy and $\mathrm{FEF}_{25-75}$ in childhood) was associated with maternal asthma (mean reduction $8.2 \%$ (95\% CI $1.3 \%$ to $15.1 \%$ ) $\mathrm{p}=0.020$ ), flow limitation (mean reduction $15.8 \%(5.8 \%$ to $25.8 \%) \mathrm{p}=0.002)$, infant onset atopy (mean reduction $11.3 \%$ (3.2\% to $19.4 \%) \mathrm{p}=0.006)$, and a history of asthma ever (mean reduction $7.3 \%$ (95\% CI $1.0 \%$ to $13.5 \%) \mathrm{p}=0.022$ ), table 2 . Current smoking was not associated with reduced lung function (data not presented). In the multivariable model, reduced lung function was associated with maternal asthma (mean reduction $9.8 \%(95 \%$ CI $3.0 \%$ to $16.5 \%)$ 
Table 1 Comparing details of those where lung function was not determined at 1, 6 and 12 months and 12 and 18 years of age ('restricted analysis' group) and the whole cohort

\begin{tabular}{|c|c|c|c|}
\hline & $\begin{array}{l}\text { Individuals where lung function was measured } \\
\text { at all ages except } 6 \text { years ( } n=91 \text { unless stated) }\end{array}$ & $\begin{array}{l}\text { Individuals where lung function was measured on } \\
\text { more than three occasions ( } n=162 \text { unless stated) }\end{array}$ & $\begin{array}{l}\text { Whole cohort } \\
\text { ( } n=253 \text { unless } \\
\text { stated) }\end{array}$ \\
\hline Percentage of male (n) & $59 \%(54)$ & $56 \%(91)$ & $56 \%(142)$ \\
\hline $\begin{array}{l}\text { Percentage with maternal history } \\
\text { of asthma ( } n)\end{array}$ & $22 \%(20)$ & $18 \%(29)$ & $20 \%(51)$ \\
\hline $\begin{array}{l}\text { Percentage with paternal history } \\
\text { of asthma (n) }\end{array}$ & $11 \%(10)$ & $14 \%(22)$ & $15 \%(35 / 242)$ \\
\hline $\begin{array}{l}\text { Percentage with mothers who } \\
\text { smoked during pregnancy ( } \mathrm{n})\end{array}$ & $25 \%(23)$ & $28 \%(45)$ & $32 \%(80 / 252)$ \\
\hline $\begin{array}{l}\text { Percentage with atopy during } \\
\text { infancy }(n)\end{array}$ & $13 \%(12)$ & $17 \%(28)^{*}$ & $13 \%(32 / 153)$ \\
\hline $\begin{array}{l}\text { Percentage with flow limitation } \\
\text { at } 1 \text { month of age }(n)\end{array}$ & $2 \%(2)^{*}$ & $10 \%(16)$ & $10 \%(23 / 243)$ \\
\hline $\begin{array}{l}\text { Mean \% \%'maxFRC at } 1 \text { month } \\
\text { (SD) }\end{array}$ & $110(52)^{*}$ & $100(48) n=155$ & $99(48) n=241$ \\
\hline $\begin{array}{l}\text { Mean \%V'maxFRC at } 6 \text { months } \\
\text { (SD) }\end{array}$ & $107(48)$ & $104(44) n=150$ & $104(46) n=192$ \\
\hline $\begin{array}{l}\text { Mean \%V'maxFRC at } 12 \text { months } \\
\text { (SD) }\end{array}$ & $95(42)$ & $98(39) n=138$ & $98(39) n=164$ \\
\hline Mean $\% \mathrm{FEF}_{25-75}$ at 6 years (SD) & $90(24)^{*}$ & $87(24) n=96^{*}$ & $85(24) n=106$ \\
\hline $\begin{array}{l}\text { Mean } \% \mathrm{FEF}_{25-75} \text { at } 12 \text { years } \\
\text { (SD) }\end{array}$ & $101(20)$ & $99(20) n=156$ & $99(20) n=183$ \\
\hline $\begin{array}{l}\text { Mean } \% \mathrm{FEF}_{25-75} \text { at } 18 \text { years } \\
\text { (SD) }\end{array}$ & $107(24)$ & $107(23) n=129$ & $107(23) n=141$ \\
\hline $\begin{array}{l}\text { Percentage of current smoker at } \\
18\end{array}$ & $21 \%(19)$ & $23 \%(30)$ & $22 \%(33 / 148)$ \\
\hline $\begin{array}{l}\text { Percentage with asthma ever by } \\
18 \text { years }\end{array}$ & $39 \%(31)^{*}$ & $46 \%(67)$ & $46 \%(80 / 172)$ \\
\hline
\end{tabular}

$\mathrm{p}=0.005)$, flow limitation (mean reduction $17.4 \% \quad(95 \% \mathrm{CI}$ $7.8 \%$ to $27.1 \%) \mathrm{p}<0.001$ ), infant onset atopy (mean reduction $12.6 \%(95 \%$ CI $4.7 \%$ to $20.5 \%) \mathrm{p}=0.002)$, and maternal smoking (mean reduction $8.1 \%$ (95\% CI $1.6 \%$ to $14.6 \%$ ) $\mathrm{p}=0.015)$, but not male gender or asthma history, table 2 . There were interactions between time and sex (mean increase in per cent lung function/year for boys compared with girls 1.0 (95\% CI 0.3 to 1.6 ) $\mathrm{p}=0.003$, figure 1 ), time and flow limitation (mean increase in per cent lung function/year for flow-limited compared to others 3.0 (95\% CI 1.9 to 4.2$) \mathrm{p}<0.001$, figure 2$)$, and time and maternal smoking during pregnancy (mean increase in $\%$ lung function/year for exposed compared to unexposed 0.9 (95\% CI 0.2 to 1.7$) \mathrm{p}=0.0181$, figure 3 ), table 3 . The online supplement presents results of analyses where $\mathrm{FEV}_{1}$ and FVC were the spirometric outcomes (see online supplementary tables E14). The online supplement also compares outcomes at age 18 years for the 13 individuals with expiratory flow limitation and the 130 without flow limitation (see online supplementary table E5); flow-limited individuals were at increased risk for wheeze in the previous year (OR 3.3 (95\% CI 1.0 to 11.1) $\mathrm{p}=0.040)$, but lung function and proportion with atopy were similar between groups. There was no interaction between V'maxFRC/FEF $25-75$ and time for the period 1 month to $\leq 6$ years (to allow comparison with an earlier study ${ }^{15}$ ). Table E6 in the online supplement presents results of the model whose results are shown in table 3 when the main effect for history of asthma and its interaction with time were added; here, lung function remained persistently lower at all ages for those with asthma. The online supplement presents data showing that lung function in the 23 individuals with highest V'maxFRC values at
1 month (by contrast with the 23 flow limited individuals) remained elevated relative to the remainder of the cohort from 1 month to 12 years (see online supplementary table E7).

\section{DISCUSSION}

This is the first study to address the question 'What factors are associated with changes in lung function within an individual throughout infancy and childhood?' There were three main findings. First, infant atopy and maternal asthma were associated with reductions in lung function from 1 month onwards. Second, relative to girls, the level of lung function in boys was initially lower but ultimately was higher and initial decrements in lung function associated with flow limitation and maternal smoking resolved over time. Third, there was no evidence of a reduction in lung function between 1 month and 18 years among those with a history of asthma. These unique results provide insight into which are the factors that may influence subsequent changes in lung function from 1 month of age, and when these changes occur.

Our results are consistent with studies which have associated early allergic sensitisation with reduced lung function in later life. A study by Illi et $a l^{25}$ reported that aeroallergen sensitisation by 3 years of age was associated with reduced lung function at 12 years of age; what our study adds is that the critical time for allergic sensitisation may be within the first year of life. We have previously demonstrated that infant onset atopy was associated with reduced $\mathrm{FEV}_{1}$ at 12 years of age, ${ }^{20}$ and results presented here suggest that onset of atopy by 6 months may be relevant to decrements in lung function. The nature of the association between atopy, reduced lung function and asthma is 
Table 2 Mean change $(95 \% \mathrm{Cl})$ in per cent predicted lung function measured at ages 1, 6 and 12 months, and 6, 12 and 18 years, associated with variables listed in the left hand column

\begin{tabular}{llll}
\hline & $\begin{array}{l}\text { Change in \% V'maxFRC/FEF } \\
\text { associated with variable (univariate } \\
\text { analysis) }\end{array}$ & $\begin{array}{l}\text { Change in \% V'maxFRC/FEF } \\
\text { associated with variable (multivariable } \\
\text { analysis) }\end{array}$ & $\begin{array}{l}\text { Change in \% V'maxFRC/FEF } 25-75 \text { associated with } \\
\text { variable (multivariable analysis including asthma } \\
\text { history term) }\end{array}$ \\
\hline Maternal asthma & $-8.2(-15.1$ to -1.3$)$ & $-9.8(-16.5$ to -3.0$)$ & $-8.9(-16.5$ to -1.3$)$ \\
Flow limitation & $\mathrm{p}=0.020$ & $\mathrm{p}=0.005$ & $\mathrm{p}=0.023$ \\
& $-15.8(-25.8$ to -5.8$)$ & $-17.4(-27.1$ to -7.8$)$ & $-10.9(-22.2$ to +0.4$)$ \\
Infant atopy & $\mathrm{p}=0.002$ & $\mathrm{p}<0.001$ & $\mathrm{p}=0.059$ \\
& $-11.3(-19.4$ to -3.2$)$ & $-12.6(-20.5$ to -4.7$)$ & $-11.9(-20.4$ to -3.4$)$ \\
Maternal smoker & $\mathrm{p}=0.006$ & $\mathrm{p}=0.002$ & $\mathrm{p}=0.006$ \\
during pregnancy & $-6.2(-12.9$ to +0.4$)$ & $-8.1(-14.6$ to -1.6$)$ & $-8.2(-15.8$ to -0.5$)$ \\
Male sex & $\mathrm{p}=0.069$ & $\mathrm{p}=0.015$ & $\mathrm{p}=0.036$ \\
& $-0.5(-6.2$ to +5.2$)$ & $-2.8(-5.0$ to +5.9$)$ & $-0.0(-6.0$ to +6.1$)$ \\
Asthma ever & $\mathrm{p}=0.860$ & $\mathrm{p}=0.877$ & $\mathrm{p}=0.987$ \\
& $-7.3(-13.5$ to -1.0$)$ & & $-6.0(-12.2$ to +0.3$)$ \\
$\mathrm{p}=0.061$
\end{tabular}

Models in the second column were univariate, models in the third column were multivariable (excluding asthma ever, where data were missing in 81 individuals), while those in the fourth right hand column included all variables.

complex, as evidenced by the presence of non-asthmatic atopics and non-atopic asthmatics, but our observations might indicate a mechanism acting at a very early developmental stage leading to early onset atopy and reduced lung function.

In a study with a design similar to ours, Bisgaard et al ${ }^{15}$ also observed reduced lung function at 1 month of age that preceded asthma symptoms but, in contrast with our study, also reported a further decrease in lung function between ages 1 month and 7 years for those with asthma. A study in Tucson observed a reduction in lung function between 2 months of age and 6 years in children with persistent wheeze. ${ }^{26}$ We did not observe a secondary decrease in lung function after early infancy in association with asthma, and there are a number of possible explanations for this apparent inconsistency between the present study and earlier reports. ${ }^{15} 26$ While it is unlikely that biological pathways will be different for our cohort and others, there are differences in populations and study designs used which might, at least partly, explain the apparently different outcomes. For example, the COPSAC study ${ }^{15}$ used a different methodology of infant lung function to that used in our study, and at 6 years of age children in our cohort had lower mean $\mathrm{FEV}_{1} / \mathrm{FVC}$ compared with 7 -year-olds in COPSAC (0.87 vs 0.95$)$, were more likely to be skin prick positive (38\% vs $19 \%)$, and to have asthma (24\% vs 16\%); these differences in study design and population characteristics make direct comparison between COPSAC and our study unreliable. Participants in the Tucson study $^{3}$ were similar to ours in terms of atopy prevalence at 6 years (38\% vs 41\%), and the same index of infant lung function was measured in both studies, albeit in a smaller number of Tucson infants $(125 \text { vs } 253)^{26}$; it is possible that with a larger

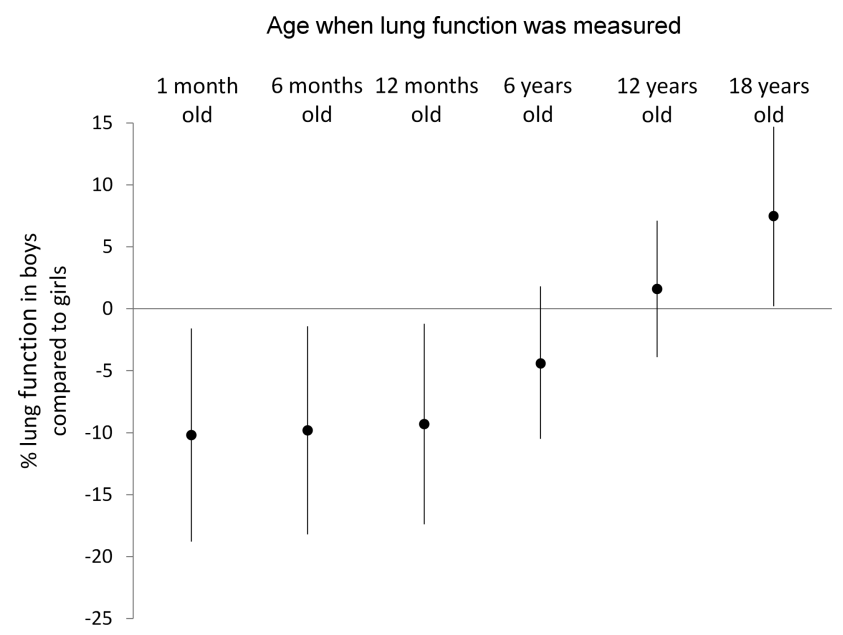

Figure 1 The mean difference in per cent of predicted lung function (circle) and $95 \%$ Cls (lines) at ages 1 month through to 18 years for boys compared with girls. The lung function measurement at 1, 6 and 12 months was maximal flow at functional residual capacity and at other ages was $\mathrm{FEF}_{25-75}$. These results were from a random coefficients model which was fitted using an unstructured covariance. The $p$ value for the interaction between lung function and time was 0.0027 . The model also included maternal asthma, infant atopy, flow limitation and maternal smoking. 


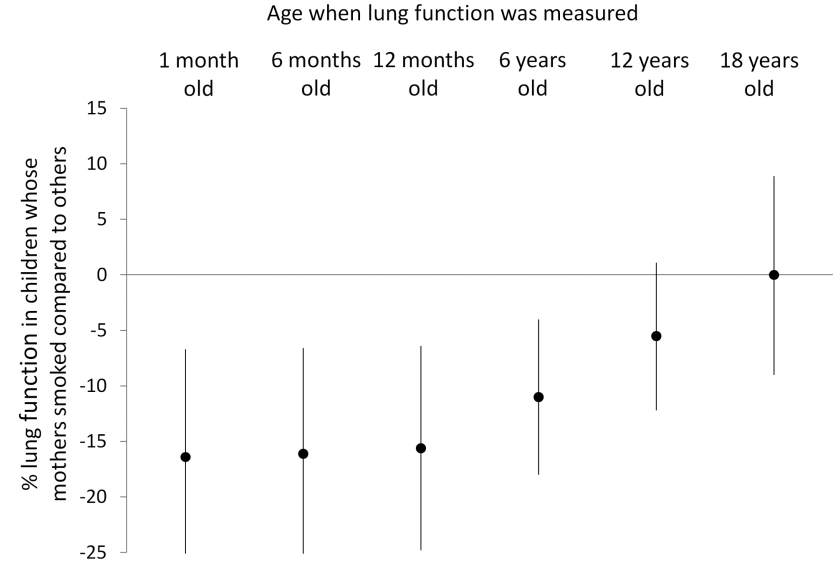

Figure 3 The mean difference in per cent of predicted lung function (circle) and 95\% Cls (lines) at ages 1 month through to 18 years for those exposed to maternal smoking during pregnancy compared to other individuals. The lung function measurement at 1, 6 and 12 months was maximal flow at functional residual capacity and at other ages was $\mathrm{FEF}_{25-75}$. These results were from a random coefficients model which was fitted using an unstructured covariance. The $p$ value for the interaction between lung function and time was 0.0181 . The model also included maternal asthma, infant atopy, sex and flow limitation.

sample size, the reduction in V'maxFRC in infancy in the group with persistent wheeze might have been significant. More studies in this area are required to resolve the question 'Is asthma associated with a reduction in lung function after one month?' since the answer is relevant to the timing of an intervention aimed at preventing reduced lung function.

At least two previous studies have reported associations between a maternal ${ }^{27}$ or a family history ${ }^{28}$ of asthma and reduced infant lung function, and here we observe that this decrease does not alter between ages 1 month and 18 years. Although an association between maternal asthma and a lower trajectory of lung function may simply reflect inherited factors, the lack of association with paternal asthma suggests a more complex mechanism. An association between childhood asthma and maternal, but not paternal, asthma has been previously reported in at least one study, ${ }^{29}$ and an explanation for this apparently inconsistent association may be an interaction between a factor in the in utero environment and maternal 'asthma genes' resulting in reduced lung function. ${ }^{30}$

Maternal smoking during pregnancy is known to be associated with reduced infant lung function, ${ }^{18}$ and in our study this difference was apparent between 1 month and 6 years of age but not thereafter (figure 3). Most mothers who smoked during pregnancy continued to smoke beyond delivery, and what this study is not able to determine is whether the apparent 'recovery' of reduced lung function in exposed individuals was due to children spending less time at home and avoiding the harmful effects of second-hand smoke, or whether despite ongoing postnatal exposure, the child's lung might apparently recover, albeit at the cost of increased respiratory symptoms while the recovery is under way. Regardless of the underlying mechanisms, these findings highlight the long-lasting harm to the lungs of the unborn child associated with maternal smoking which can potentially be avoided by smoking cessation in early pregnancy. ${ }^{31}$

We have previously described that the reduction in lung function associated with flow limitation in early infancy resolves by 12 years of age, ${ }^{23}$ and here we confirm that at 18 years of age,

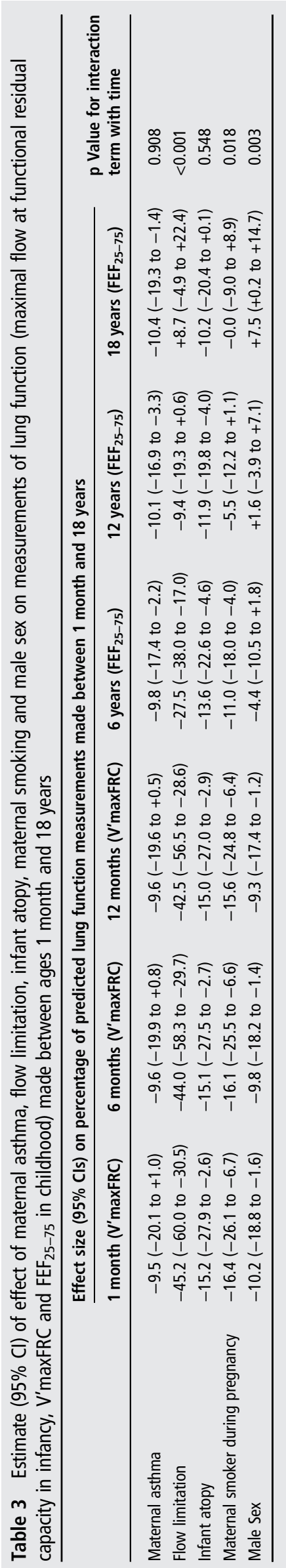


lung function is similar to those without neonatal flow limitation. The mechanism whereby flow limitation apparently resolves is unclear, but we do not believe this is necessarily regression to the mean; differences in lung function for the flow-limited group, and also individuals with the highest V'maxFRC values at 1 month, persisted for at least 6 years, and regression to the mean might be expected to occur much more rapidly. The flow-limited group were at increased risk for wheeze at 18 years but not at increased risk for atopy or reduced lung function, suggesting alternative mechanisms for symptoms and initial reduced lung function, such as oedema or delayed growth.

When compared with females, males have reduced lung function in infancy ${ }^{18}$ but increased lung function in adulthood, ${ }^{32}$ and ours is the first longitudinal study to describe this inversion of the relationship between sex and reduced lung function. Male sex is associated with increased risk for remission of childhood asthma, ${ }^{33}$ and we confirmed assumptions made from cross-sectional studies that at least part of the mechanism for resolution of asthma symptoms in boys is due to an increase in lung function over time relative to girls.

There are a number of factors which need to be considered when interpreting these results. The main limitation was the missing measurements of pulmonary function. The random coefficients model approach assumes missing at random, but this analysis cannot completely eliminate the effect of bias meaning that our results might not necessarily be generalisable. We have demonstrated that missingness did not bias the population for important determinants of lung function, sex, parental asthma, maternal smoking. Moreover, measurements of lung function at all times before and after 6 years of age were not biased by missing data and, therefore, the overall trajectory of lung function from infancy to 18 years is unlikely to be substantially influenced by the modest increase in lung function at 6 years seen among those with more complete data.

In summary, this is the first study to give insight into which factors are associated with a change in the trajectory of lung function from 1 month to 18 years, and when these factors might be important.

Correction notice This article has been corrected since it was published Online First. The author Des Cox has been updated to Des W Cox.

Acknowledgements We are very grateful to the study participants and their parents for their ongoing enthusiasm for this study. We would also like to thank the many colleagues who have been involved in assessments of this cohort over the years including Sally Young, Steve Stick, John Henderson, Gary Geelhoed, Moreen Cox, Lyle Palmer, Neil Gibson and Veena Judge.

Contributors PleS, LL and JG conceived the study and obtained funding for the assessments. ST, DWC and DM undertook the assessments of the cohort at ages 12 and 18 years. ST analysed the data and wrote the first draft. All authors made meaningful contributions to the final manuscript.

Funding This study was made possible due to funding from the National Health and Medical Research Council of Australia.

Competing interests None.

Ethics approval Medical Ethics Committee of Princess Margaret Hospital.

Provenance and peer review Not commissioned; externally peer reviewed.

\section{REFERENCES}

1 Sears MR, Greene JM, Willan AR, et al. A longitudinal, population-based, cohort study of childhood asthma followed to adulthood. $N$ Engl J Med 2003:349:1414-22

2 Oswald H, Phelan PD, Lanigan A, et al. Childhood asthma and lung function in mid-adult life. Pediatr Pulmonol 1997;23:14-20.
3 Stern DA, Morgan WJ, Wright AL, et al. Poor airway function in early infancy and lung function by age 22 years: a non-selective longitudinal cohort study. Lancet 2007:370:758-64.

4 Mullane D, Turner SW, Cox D, et al. Reduced infant lung function, active smoking, and wheeze in 18-year-old individuals. J Am Med Assoc Pediatr 2013; 167:368-73

5 Friedrich L, Pitrez PM, Stein RT, et al. Growth rate of lung function in healthy preterm infants. Am J Respir Crit Care Med 2007;176:1269-73.

6 Turner S, Prabhu N, Danielian P, et al. First and second trimester fetal size and asthma outcomes at age ten years. Am J Respir Crit Care Med 2011;184:407-13.

7 Fletcher C, Peto R. The natural history of chronic airflow obstruction. Brit Med J 1977;1:1645-8.

8 James AL, Palmer LJ, Kicic E, et al. Decline in lung function in the Busselton Health Study: the effects of asthma and cigarette smoking. Am J Respir Crit Care Med 2005;171:109-14.

9 Kohansal R, Martinez-Camblor P, Agusti A, et al. The natural history of chronic airflow obstruction revisited: an analysis of the Framingham offspring cohort. Am J Respir Crit Care Med 2009;180:3-10.

10 Grol MH, Gerritsen J, Vonk JM, et al. Risk factors for growth and decline of lung function in asthmatic individuals up to age 42 years. A 30 -year follow-up study. Am J Respir Crit Care Med 1999;160:1830-7.

11 Tennant PW, Gibson GJ, Parker L, et al. Childhood respiratory illness and lung function at ages 14 and 50 years: childhood respiratory illness and lung function. Chest 2010;137:146-55

12 Hallberg J, Anderson M, Wickman M, et al. Factors in infancy and childhood related to reduced lung function in asthmatic children: a birth cohort study (BAMSE). Pediatr Pulmonol 2010;45:341-8.

13 Xuan W, Peat JK, Toelle BG, et al. Lung function growth and its relation to airway hyperresponsiveness and recent wheeze. Results from a longitudinal population study. Am J Respir Crit Care Med 2000;161:1820-4.

14 Turner S, Zhang G, Young S, et al. Associations between postnatal weight gain, change in postnatal pulmonary function, formula feeding and early asthma. Thorax 2008;63:234-9.

15 Bisgaard $H$, Jensen SM, Bonnelykke K. Interaction between asthma and lung function growth in early life. Am J Respir Crit Care Med 2012;185:1183-9.

16 Ferris BG. Epidemiology Standardization Project (American Thoracic Society). Am Rev Respir Dis 1978;118:1-120.

17 Young S, Le Souëf PN, Geelhoed GC, et al. The influence of a family history of asthma and parental smoking on airway responsiveness in early infancy. $N$ Eng/ J Med 1991;324:1168-73

18 Young S, Sherrill DL, Arnott J, et al. Parental factors affecting respiratory function during the first year of life. Pediatr Pulmonol 2000;29:331-40.

19 Pepys J. Skin tests for immediate, type I, allergic reactions. Proc Roy Soc Med 1972;65:271-2.

20 Turner SW, Heaton T, Rowe J, et al. Early-onset atopy is associated with enhanced lymphocyte cytokine responses in 11-year-old children. Clin Exp All 2007:37:371-80

21 Gardner RM, Hankinson JL, Clausen JL, et al. Standardisation of spirometry-1987 update. Am Rev Respir Dis 1987;136:1285-98.

22 Stanojevic S, Wade A, Stocks J, et al. Reference ranges for spirometry across all ages: a new approach. Am J Respir Crit Care Med 2008;177:253-60.

23 Turner SW, Palmer LJ, Rye PJ, et al. Infants with flow limitation at 4 weeks: outcome at 6 and 11 years. Am J Respir Crit Care Med 2002;165:1294-8.

24 Turner SW, Young $S$, Landau $L$, et al. Reduced lung function both before bronchiolitis and at 11 years. Arch Dis Child 2002;87:417-20.

25 Illi S, von Mutius E, Lau S, et al. Perennial allergen sensitisation early in life and chronic asthma in children: a birth cohort study. Lancet 2006;368:763-70.

26 Martinez FD, Wright AL, Taussig LM, et al. Asthma and wheezing in the first six years of life. The Group Health Medical Associates. N Engl J Med 1995; 332:133-8

27 Dezateux C, Stocks J, Dundas I, et al. Impaired airway function and wheezing in infancy: the influence of maternal smoking and a genetic predisposition to asthma. Am J Respir Crit Care Med 1999;159:403-10.

28 Stick SM, Burton PR, Gurrin L, et al. Effects of maternal smoking during pregnancy and a family history of asthma on respiratory function in newborn infants. Lancet 1996;348:1060-4.

29 Litonjua AA, Carey VJ, Burge HA, et al. Parental history and the risk for childhood asthma. Does mother confer more risk than father? Am J Respir Crit Care Med 1998;158:176-81.

30 Ober C, Thompson EE. Rethinking genetic models of asthma: the role of environmental modifiers. Curr Opin Immunol 2005;17:670-8.

31 Prabhu N, Smith N, Campbell D, et al. First trimester maternal tobacco smoking habits and fetal growth. Thorax 2010;65:235-40.

32 Knudson RJ, Lebowitz MD, Holberg CJ, et al. Changes in the normal maximal expiratory flow-volume curve with growth and aging. Am Rev Respir Dis 1983;127:725-34.

33 Andersson $\mathrm{M}$, Hedman L, Bjerg $\mathrm{A}$, et al. Remission and persistence of asthma followed from 7 to 19 years of age. Pediatr 2013;132:e435-42. 